\title{
Fortnightly Review
}

\section{Acute circulatory support}

\author{
Matthew J Barnard, Stephen P K Linter
}

Numerous drugs can increase cardiac output, thereby improving tissue oxygen delivery, but often they do this at the expense of increasing myocardial oxygen demand. This may be critical when cardiac function is substantially impaired or ischaemia is the precipitating cause. Using polypharmacy to substantially improve cardiovascular status requires detailed knowledge of the pharmacodynamics and interactions of the available agents so that they may be tailored to the individual patient. In some settings combinations of inotropes and vasodilators may be desirable to minimise cardiac workload. In other instances vasopressors may be necessary to urgently reviews the use of this group of drugs as well as the mechanical assist devices that may be used when drugs fail.

The management of acute heart failure and the ensuing low cardiac output state remains a fundamental challenge in cardiac intensive care. When oxygen delivery declines tissue requirements are initially maintained by an increased oxygen extraction. However, below a critical level of delivery consumption falls (supply dependency) ${ }^{1}$ and anaerobic metabolism and lactate production ensue. Multiple organ failure develops if cardiac function is inadequate for an appreciable period.

Treatment is aimed at increasing cardiac output and tissue oxygen delivery to a viable level, thus restoring vital organ function. Packed cell volume, heart rate, and fluid management should be optimised with invasive monitoring techniques. ${ }^{2}$ Positive pressure ventilation may improve oxygenation, reduce oxygen demands, and decrease left ventricular afterload. ${ }^{3}$ Reducing afterload with vasodilators increases cardiac output, ${ }^{4}$ but this approach is often limited by hypotension. Pharmacological enhancement of contractility and mechanical augmentation of stroke volume are the final means of treating acute heart failure. We review the non-digitalis positive inotropic drugs and temporary mechanical pumps that are useful for this purpose.

Harefield Hospital, Harefield, Middlesex UB9 6JH

Matthew J Barnard, clinical fellow in cardiac anaesthesia and intensive care Stephen P K Linter, consultant anaesthetis

Correspondence to: Dr Barnard.

BMF 1993;307:35-41

\section{Catecholamines}

Catecholamines retain a primary position in the treatment of acute heart failure by virtue of their pharmacokinetic properties, predictable pharmacodynamic responses, and wide range of haemodynamic effects. The half life of most agents is two to three minutes, ensuring that steady state infusion concentrations are reached within 10 to 15 minutes. ${ }^{5}$ Infusion rates are linearly related to plasma concentrations, which are directly related to pharmacodynamic restore a minimum perfusion pressure. This paper

effects. ${ }^{6}$ The haemodynamic effects are predictable from a knowledge of their activity at autonomic receptors (see table).

Activity of catecholamines at adrenergic receptors

\begin{tabular}{lccccc}
\hline & Dopamine & Dopamine & & & \\
& 1 & 2 & $\beta_{1}$ & $\beta_{2}$ & $\alpha$ \\
\hline Dopexamine & ++ & + & 0 & +++ & 0 \\
Dopamine & +++ & +++ & ++ & + & +++ \\
Dobutamine & 0 & 0 & +++ & ++ & + \\
Noradrenaline & 0 & 0 & +++ & 0 & ++ \\
Adrenaline & 0 & 0 & +++ & ++ & +++ \\
Isoprenaline & 0 & 0 & +++ & +++ & 0 \\
\hline
\end{tabular}

$0=$ No agonism. $+=$ Mild agonism. $++=$ Moderate agonism.

$+++=$ Pronounced agonism.

Response to catecholamine infusions may be limited by the reduction in $\beta$ receptor density and function (down regulation) which occurs with chronic sympathetic stimulation. ${ }^{7}$ The defect in $\beta$ receptor responses has been attributed to a $30 \%$ increase in activity of the inhibitory form of the $G$ regulatory protein acting on adenyl cyclase. $^{8}$

\section{DOPAMINE}

Dopamine is a naturally occurring sympathetic amine which is the endogenous precursor of noradrenaline. At low doses $(<4 \mu \mathrm{g} / \mathrm{kg} / \mathrm{min})$ dopamine predominantly activates dopamine 1 and dopamine 2 receptors, increasing renal plasma flow, the glomerular filtration rate, and sodium excretion. $\beta_{1}$ Receptors are stimulated at doses between 4 and $10 \mu \mathrm{g} / \mathrm{kg} / \mathrm{min}$, resulting in an increased heart rate and cardiac output. At doses greater than $10 \mu \mathrm{g} / \mathrm{kg} / \mathrm{min} \alpha$ receptor activation leads to vasoconstriction and raised systemic and ventricular filling pressures, which may result in ischaemia. Dopamine is often used as the first choice for treating shock as it increases inotropy while also restoring perfusion pressure to vital organs. It is useful in low dosage for augmenting renal blood flow, particularly in combination with other agents. ${ }^{9}$ Dopamine may preserve renal function in shock states when noradrenaline has been used to raise systemic pressure. $^{10}$

\section{DOBUTAMINE}

Dobutamine is a synthetic catecholamine with pronounced $\beta_{1}$ agonist effects and weak $\beta_{2}$ effects. We now know it to be a racemic mixture of laevo and dextro isomers which differ in adrenergic receptor affinities. The laevo isomer is predominantly an $\alpha$ agonist, whereas the dextro isomer is a potent $\beta_{1}$ and $\beta_{2}$ agonist. ${ }^{11}$ Dobutamine increases contractility via its $\beta$ effects, thus raising cardiac output, stroke volume, and (at higher doses) heart rate. Peripheral vasodilatation is well demonstrated by an increase in cardiac output 
when the drug is given to animals with artificial hearts. ${ }^{12}$ Diastolic filling pressures are lowered and left ventricular wall tension and cavity size decline.

Dobutamine improves ventricular perfusion without exacerbating myocardial injury in patients after infarction ${ }^{13}$ and decreases infarct size in animal coronary ligation models. ${ }^{14}$ The consensus of several animal and human studies is that overall dobutamine improves the myocardial oxygen supply and demand balance if tachycardia is avoided. ${ }^{6}$

\section{ADRENALINE}

Adrenaline is an endogenous catecholamine secreted by the adrenal medulla. It is a very potent $\alpha$ and $\beta_{1}$ agonist and moderate $\beta_{2}$ agonist. $\beta$ Effects predominate at doses of between 0.04 and $0.1 \mu \mathrm{g} / \mathrm{kg} / \mathrm{min}$, resulting in increased heart rate and contractility with an unchanged or lowered total peripheral resistance. At higher doses $\alpha$ effects prevail, resulting in raised peripheral resistance and blood pressure. Although it dilates myocardial arterioles and venules, the increases in rate, contractility, and vascular resistance may result in myocardial ischaemia. Concomitant treatment with a vasodilator may counteract the $\alpha$ mediated vasoconstriction, ${ }^{15}$ thus improving the myocardial oxygen supply to demand ratio. Adrenaline may increase coronary perfusion pressure in a shocked patient with a low diastolic blood pressure, thus ameliorating myocardial ischaemia.

Adrenaline's usefulness relates to its greater maximal effects (efficacy) than other $\beta$ agonists. It is indicated in patients who do not respond to dobutamine or dopamine and in patients with life threatening hypotension. Its efficacy combined with useful bronchodilatory effects makes it the drug of choice in anaphylaxis. ${ }^{16}$

\section{NORADRENALINE}

Noradrenaline is an endogenous catecholamine secreted by the adrenal medulla. It is the main neurotransmitter at sympathetic postganglionic fibres. It is a potent $\beta_{1}$ agonist and very potent $\alpha_{1}$ and $\alpha_{2}$ agonist. Administration of noradrenaline leads to a rise in contractility (mediated by $\alpha$ receptors) ${ }^{17}$ and a substantial increase in systemic vascular resistance, which may decrease cardiac output. Blood pressure increases and heart rate may decline via baroreceptor mediated reflexes. Myocardial oxygen consumption is increased, and noradrenaline may exacerbate ischaemia and compromise ventricular function. Simultaneous treatment with a vasodilator may counteract the rise in vascular resistance, resulting in a net increase in contractility alone. ${ }^{18}$ Pulmonary vascular resistance is increased by noradrenaline. However, its use has been paradoxically advocated in severe right ventricular failure. ${ }^{19}$ Epoprostenol infusion into the right atrium and noradrenaline infusion into the left atrium lowered pulmonary but not systemic vascular resistance..$^{20}$

Noradrenaline is used in settings where the importance of increasing perfusion pressure outweighs the disadvantages of lowering cardiac output, or to counterbalance vasodilatory effects of other agents.

\section{ISOPRENALINE}

Isoprenaline is a synthetic catecholamine with the most potent direct $\beta_{1}$ and $\beta_{2}$ agonist effects and no $\alpha$ effects. Administration results in improved contractility and a pronounced increase in heart rate and cardiac output. Systemic vascular resistance is reduced, resulting in a decline in systemic and diatolic blood pressure.

Undesirable effects include tachycardia, a propensity towards arrhythmias, and a diversion of blood flow from vital organs to muscle and skin. Isoprenaline can reduce the myocardial oxygen supply to demand ratio and may produce coronary steal. Isoprenaline is useful in patients with bradycardia and atrioventricular block, particularly in denervated hearts. ${ }^{21}$ It may, however, worsen Mobitz type II block. ${ }^{22}$ Pulmonary vasodilatory effects make it useful in the treatment of pulmonary hypertension and right ventricular failure, particularly in patients with cardiac transplants. ${ }^{23}$ Isoprenaline decreases carotid and coronary blood flow during resuscitation from cardiac arrest, when it should be used with caution..$^{22}$

\section{DOPEXAMINE}

Dopexamine is a synthetic catecholamine with pronounced $\beta_{2}$ agonism (60 times as potent as dopamine), negligible $\beta_{1}$ agonism, no $\alpha$ effects, significant dopamine 1 receptor activation (one third the potency of dopamine), and mild dopamine 2 receptor activation. ${ }^{24}$ In addition, it is a potent reuptake inhibitor of neurally released catecholamines.

Cardiovascular responses to dopexamine infusion include increased heart rate and cardiac index. The increase in left ventricular contractility is less than that evoked by dobutamine, but there is a greater decline in systemic and pulmonary vascular resistance. ${ }^{25}$ Diastolic filling pressures fall and mean arterial pressure usually changes by less than $10 \%$. Dopexamine augments renal blood flow with one third the potency of dopamine, but this effect declines at doses over $2 \mu \mathrm{g} / \mathrm{kg} / \mathrm{min} .{ }^{26}$ Possibly the dopamine 1 receptor mediated natriuretic effects are opposed by a tubular $\beta_{2}$ agonist effect. ${ }^{27}$ Dopexamine decreases the incidence of postoperative renal failure in orthotopic liver transplant recipients. ${ }^{28}$ Other benefits of dopexamine include an increase in hepatosplanchnic blood flow..$^{29}$ This has aroused interest because of an appreciation of the importance of splanchnic vasoconstriction and ischaemia in the pathogenesis of multiorgan failure. ${ }^{30}$ Dopexamine increases oxygen delivery and consumption and decreases plasma lactate concentrations when combined with noradrenaline in patients with septic shock. ${ }^{31}$

Overall dopexamine should be regarded as an inodilator with haemodynamic effects similar to those of the phosphodiesterase inhibitors. It is used as an alternative to dobutamine to increase cardiac output and produce vasodilation, particularly in the renal and mesenteric beds.

\section{Newer agents}

The search for inotropic drugs which enhance systemic flow and provide some degree of renal protection but lack undesirable vasoconstrictor effects has led to the development of several novel dopaminergic agents. Fenoldopam is a dopamine 1 receptor agonist with no $\alpha$ or $\beta$ effects. It is 10 times more potent than dopamine at dopamine 1 receptors. ${ }^{32}$ It increases the cardiac index and produces dose dependent reductions in systemic vascular resistance and blood pressure. Renal blood flow increases by $40 \%$. Ibopamine is a compound which is metabolised to epinine, a dopamine 1 receptor agonist with some activity at $\alpha$ and $\beta$ receptors. Overall it is a vasodilating mild positive inotrope. ${ }^{32}$

Orally effective sympathomimetic drugs include terbutaline, pirbuterol, prenalterol, TA-064, butopamine, ibopamine, and dopexamine. They have no current place in the treatment of acute heart failure.

Colforsin directly stimulates sarcolemmal adenylate cyclase and is a moderate inotrope and vasodilator. Investigations are being carried out into agents such as MCI-154 which sensitise the contractile apparatus to calcium. ${ }^{33}$ 


\section{Phosphodiesterase inhibitors}

The phosphodiesterase inhibitors are a group of potent intropic and vasodilating agents, often referred to as inodilators. There are three groups of phosphodiesterase inhibitors: the bipyridine inhibitors amrinone and milrinone; the imidazole derivatives enoximone and piroximone; and the benzimidazole derivatives sulmazole, pimobendan, and adibendan.

These agents selectively and competitively inhibit cyclic nucleotidase phosphodiesterase F III in cardiac and vascular smooth muscle. ${ }^{34}$ This enzyme exists in two isoforms, of which enoximone inhibits only the cyclic guanosine monophosphate sensitive form. ${ }^{35}$ A rise in the intracellular concentration of cyclic adenosine monophosphate seems to be the important mechanism mediating positive inotropy, though this remains controversial. ${ }^{36}$ Phosphodiesterase inhibitors produce no alteration in calcium sensitivity as assayed in chemically skinned myofibrils. ${ }^{32}$

Phosphodiesterase inhibitors increase stroke volume and cardiac output by increasing inotropy while decreasing systemic and pulmonary vascular resistance, without altering heart rate. The decrease in impedance to left ventricular ejection and the rise in contractility lower myocardial wall tension, oxygen consumption, and diastolic filling pressures. Phosphodiesterase inhibitors have a unique beneficial effect on the diastolic properties of the left ventricle, as manifested by improved relaxation, compliance, and filling. An improvement in relaxation (lusitropy), as regulated by load, inactivation, and non-uniformity, is achieved at lower doses than those necessary for inotropic effects. $^{37}$

The inotropic effects of the phosphodiesterase inhibitors have been challenged with suggestions that the improvements in cardiac performance are attributable to vasodilatation alone ${ }^{38}$ However, there is now ample evidence for an independent positive inotropic effect. ${ }^{39}$ Analysis of effects on the pressure-volume relation shows that phosphodiesterase inhibitors are useful in right heart failure. They can increase cardiac index by $30 \%$ while decreasing mean pulmonary artery pressure by $10 \%$ and pulmonary vascular resistance by $40 \% .{ }^{37}$ Others have recorded similar effects in patients with mitral stenosis and in those with previously unresponsive pulmonary hypertension. ${ }^{40}$

At high doses substantial reductions in mean arterial pressure may occur. This effect may be minimised by volume expansion, slower administration of loading doses, and giving vasopressors such as noradrenaline. ${ }^{35}$ Nevertheless, enoximone has been used successfully in shock. ${ }^{41}$

The benzimidazole derivatives combine phosphodiesterase inhibition with calcium sensitising properties.

Development of the phosphodiesterase inhibitors has effectively been halted by evidence of adverse effects on long term survival. Oral administration of milrinone to patients with chronic heart failure worsened symptoms and increased mortality by $30 \%{ }^{42}$ Smaller studies with milrinone and amrinone yielded similar results. ${ }^{43}$ This report raises important points concerning the treatment of severe heart failure. Investigations in rats showing improved survival are attributable to exclusive peripheral vasodilatation without positive inotropy. ${ }^{44}$ The benefit of manipulating myocardial energetics in the failing heart is now being questioned. Cyclic adenosine monophosphate concentrations are depleted in patients with incapacitating ventricular failure, but this may be a protective mechanism. ${ }^{45}$

Despite these considerations most authorities consider that there is no evidence that short term intravenous infusions of phosphodiesterase inhibitors worsen mortality in acute heart failure. ${ }^{46} \mathrm{We}$ believe, however, that long term follow up of patients who have been given short term infusions is warranted before they can be recommended without reservation.

Amrinone is a bipyridine with an elimination half life of greater than two hours. Electrophysiological study shows a decrease in the atrial and atrioventricular functional refractory period. ${ }^{47}$ Side effects of oral amrinone limit its usefulness and include arrhythmias, thrombocytopenia, gastrointestinal disturbances, and liver function abnormalities. ${ }^{48}$

Milrinone is a second generation bipyridine derivative of amrinone and is 15 times more potent than amrinone. It increases renal and splanchnic blood flow. ${ }^{49}$ Its half life is two hours; side effects include fluid retention and arrhythmias at high doses. ${ }^{39}$

Enoximone is an imidazole with an elimination half life of four hours. It is metabolised by sulphoxidation to a substance with inotropic and vasodilatory properties with 0.14 times the potency and 13 times the duration of the parent compound.

Phosphodiesterase inhibitors significantly improve the cardiac index and have favourable effects on diastolic filling pressures, isovolumic relaxation, myocardial oxygen consumption, and pulmonary vascular resistance, usually without causing tachycardia or receptor down regulation. We recommend them as first line agents in patients with adequate filling pressures and without pre-existing severe vasodilatation. Simultaneous administration of vasoconstrictors may be necessary to avoid hypotension. The effects of phosphodiesterase inhibitors and catecholamines are additive and synergistic. ${ }^{50}$ Infusions of amrinone with noradrenaline, ${ }^{51}$ dopamine, ${ }^{52}$ and dobutamine ${ }^{53}$ have all shown improved perfusion and attenuation of the vasoconstrictive effects of the adrenergic agents.

\section{Pharmacological strategy}

Recently the classification of shock states has altered from a division into aetiological groups such as cardiogenic, hypovolaemic, and septic to an emphasis on pathophysiological alterations in oxygen delivery and utilisation.' Similarly, the selection of appropriate agents for clinical settings is dictated by individual haemodynamic derangements rather than by the specific diagnosis. This requires assessment variously of heart rate, systemic and pulmonary arterial pressures, filling pressures, cardiac output, vascular resistances, and stroke work.

Pharmacological treatment, however, is affected by the importance of myocardial ischaemia. In ischaemia the end systolic pressure volume line is shifted to the right (decreased ejection) and the end diastolic line is shifted to the left (decreased filling) (fig 1). Sympathomimetics will restore both of these indices at the possible expense of increased myocardial oxygen requirement and decreased supply owing to tachycardia. After myocardial infarction or cardiac surgery we use a three step approach. Vasodilators are the first

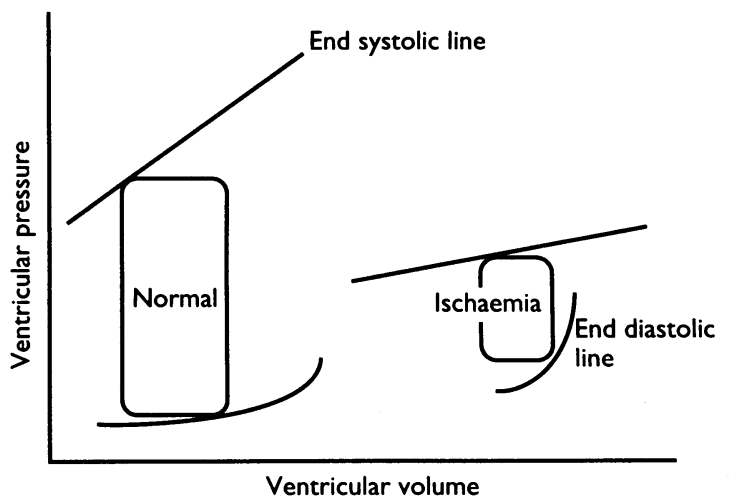

FIG 1-Volume pressure loops 


\section{Box A}

Indications for intra-aortic balloon pump insertion

- Perioperative insertion in cardiac surgery

High risk patients with severe ventricular dysfunction

Refractory angina

Aneurysmectomy

Facilitation of separation from cardiopulmonary bypass

Donor dysfunction after cardiac transplantation

- Ischaemia

Refractory angina

Myocardial infarction with cardiogenic shock

Ventricular septal defect after infarction

Papillary muscle dysfunction or rupture

- Prophylaxis in high risk patients

Angioplasty

Preoperatively in patients with severe ventricular dysfunction

choice, with the intention of increasing stroke volume, reducing myocardial oxygen demand, and possibly ameliorating ischaemia. Phosphodiesterase inhibitors may be used to the maximum dose that systemic blood pressures tolerate. It is crucial that the patients are normovolaemic, as vigorous diuretic therapy and prolonged fasting often result in volume depletion in this group. Hypotension due to vasodilation may be severe and is unpredictable. Adding noradrenaline in this setting is rational, as the combination results in a net increase in contractility and may be titrated to the degree of systemic vasodilation. However, there is little evidence that combinations of drugs with opposing effects on the peripheral vasculature selectively improve perfusion to vital organs.

Second line management utilises dobutamine for its inotropic and ventricular-vascular coupling effects. Myocardial contractility, ejection phase indices, and diastolic function are favourably influenced by dobutamine. ${ }^{54}$ In patients having cardiac surgery dobutamine increases cardiac output and decreases systemic and pulmonary vascular resistance to a greater degree than dopamine and has less chronotropicity than dopamine, adrenaline, and isoprenaline. Several workers have contrasted the increase in ventricular end diastolic pressure produced by dopamine with the usual fall associated with dobutamine. ${ }^{55}$ Dobutamine reduces infarct size whereas dopamine may enhance it. ${ }^{56}$ Heart rate must be closely monitored.

Finally, adrenaline and noradrenaline are used as a last resort when hypotension threatens vital organ function, as manifested by tachycardia, acidaemia, oliguria, peripheral cooling, altered cerebration, and desaturation. Isoprenaline is used only to control an inappropriately slow heart rate.

In conditions such as sepsis or shock states secondary to surgical catastrophe in which ischaemia is not a critical precipitating factor other considerations arise. Septicaemic shock is characterised by increased cardiac output and greatly reduced systemic vascular resistance. The potency and efficacy of adrenaline ensure its usefulness in increasing cardiac output and arterial pressure, while the increase in afterload may be enough to restore blood pressure in some moderately vasodilated patients. However, severe vasomotor paralysis usually necessitates vasoconstriction with noradrenaline. The minimum dose necessary to restore perfusion pressure is used, as noradrenaline usually decreases cardiac output and particularly compromises renal blood flow. We never begin noradrenaline infusions without assessing haemodynamic parameters with a pulmonary artery catheter.

\section{Intra-aortic balloon counterpulsation}

The concept of counterpulsation was first advanced in $1958,{ }^{57}$ and Kantrowitz et al reported clinical success with the intra-aortic balloon pump in $1968 .{ }^{58} \mathrm{~A}$ balloon is positioned in the descending aorta, just distal to the left subclavian artery, and inflated with $50 \mathrm{ml}$ carbon dioxide or helium at the onset of diastole. This results in displacement of blood into the proximal and distal aorta, increasing diastolic aortic pressures. Rapid deflation before systole decreases aortic pressures and reduces the impedance to left ventricular ejection, thus unloading the left ventricle. Diastolic augmentation of blood flow increases cardiac output (by some 20-50\%); coronary, cerebral, and renal perfusion; left ventricular stroke work index; and ejection fraction. Systolic arterial pressure, left ventricular wall tension, and end diastolic filling pressure and volume decline. Myocardial oxygen supply increases while demand decreases. The intra-aortic balloon pump ameliorates myocardial ischaemia, increases watershed perfusion in acute myocardial infarction, and possibly decreases infarct size. ${ }^{57}$

Box A outlines the indications for intra-aortic balloon pump placement. Insertion usually occurs via the femoral artery and may be percutaneous or surgical. Balloon inflation may be triggered from the $\mathbf{R}$ wave of the electrocardiogram (to coincide with the peak of the $T$ wave), from an arterial trace, or at an intrinsic set rate. Balloon inflation should occur at closure of the aortic valve-that is, at the dicrotic notch. Premature inflation will increase impedance to left ventricular ejection. Delay in inflation will needlessly decrease diastolic augmentation. Automatic adjustment of inflation has been described. ${ }^{59}$

Complications with intra-aortic balloon pumps are frequent and may be severe. Up to $36 \%$ of patients may suffer vascular complications. ${ }^{60} \mathrm{Leg}$ ischaemia is the most common and may require removal of the balloon and embolectomy. A greater incidence occurs in patients with diabetes, in peripheral vascular disease, and in women and possibly with percutaneous insertion. ${ }^{61}$ Arterial injury and aortic dissection occur in fewer than $5 \%$ of cases, though necropsy studies indicate that many instances of aortic dissection are not clinically recognised. ${ }^{61}$ Preventing thromboembolisation requires full anticoagulation and avoidance of balloon non-inflation. Thrombocytopenia and haemolysis may occur, and infectious complications are manifested in $1-3 \%$ of patients. ${ }^{61}$

\section{Ventricular assist devices}

The intra-aortic balloon pump will not be effective in patients with a cardiac index below $1.41 / \mathrm{m}^{2} / \mathrm{min}$. These patients may benefit from one of the mechanical pumps designed for short term use-the ventricular assist devices. These pumps have evolved directly from heart-lung bypass machines developed for cardiac surgery. They may be classified in several ways (box B).

Patient selection is the most important determinant of a successful outcome. Indications for insertion of a ventricular assist device include failure to wean from cardiopulmonary bypass, cardiogenic shock after infarction or myocarditis, as a bridge to transplantation, and cardiac allograft failure. Clinical criteria for insertion of a ventricular assist device at this hospital are listed in box $\mathrm{C}$ and are similar to those used elsewhere.

Absolute contraindications to ventricular assist devices include multiorgan failure, septic shock, and irreversible brain damage. Relative contraindications include cardiopulmonary bypass longer than five hours, age over 70 , coagulopathy, renal failure, and localised infection. 

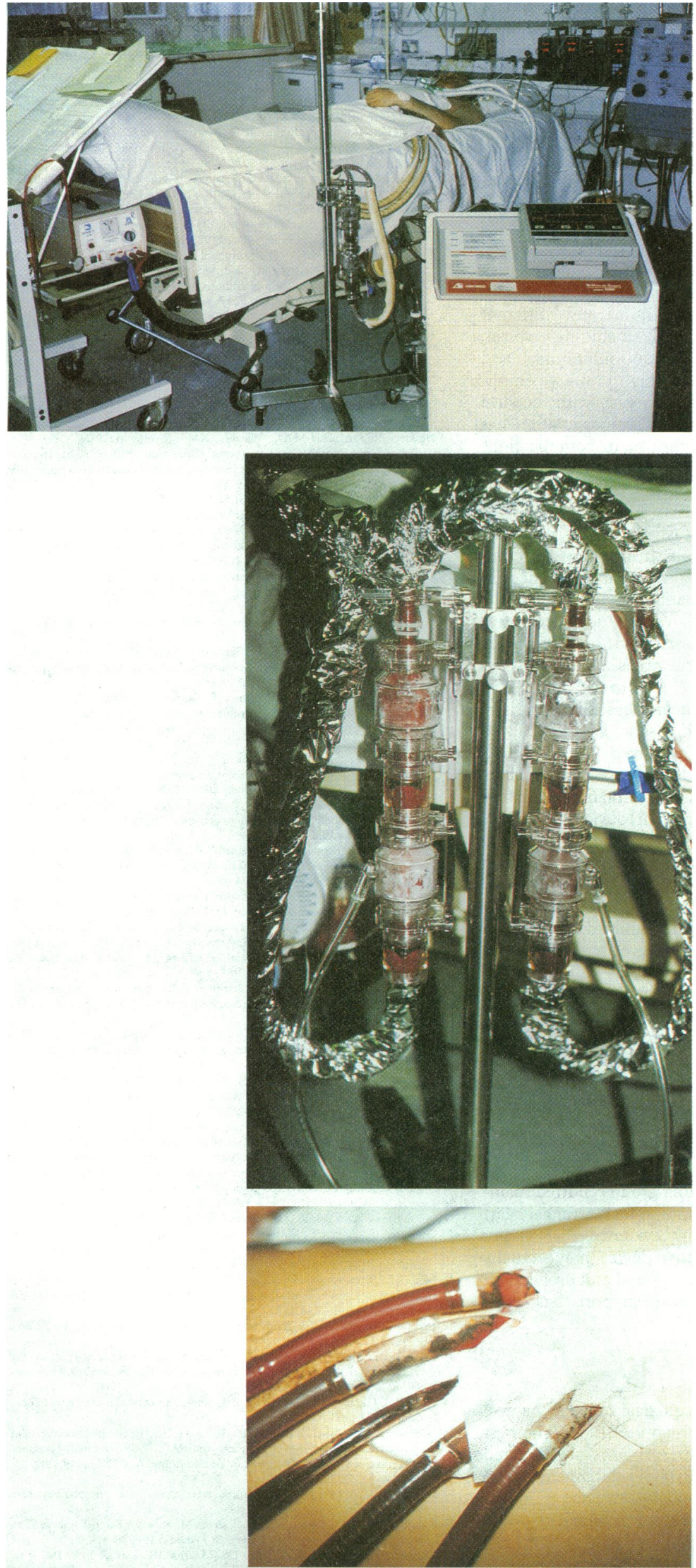

FIG 2-Abiomed biventricular support system. Top: Patient connected to system. Middle: Enlarged view of pneumatic pumps. Left pump contains oxygenated blood. Bottom: Canula insertion sites under costal margin
The Abiomed BVS 5000, a biventricular support system, is the device most often used at this hospital (fig 2). It is a gravity filled, pneumatically driven, external prosthetic ventricle with an electromechanical console. Gravity filling allows the ventricular rate to adjust to venous return, in a fill to empty mode, avoiding pulmonary-systemic imbalance when providing biventricular assist. The Abiomed was the first device to receive approval from the United States Food and Drug Administration for postcardiotomy ventricular dysfunction. Of 347 patients given support with this device, 93 survived to hospital discharge. ${ }^{62}$

The Biomedicus Centrifugal Pump is an external vortex device providing non-pulsatile flow, utilising an electrically powered magnetic impeller. It is easy to apply, relatively cheap, and can provide high flow rates. Non-pulsatile pumps are rarely used for longer than one to two weeks, usually after cardiotomy. A degree of success ( $31 \%$ survival greater than 30 days) was reported in 67 patients after placement in an emergency or cardiac arrest setting. ${ }^{63}$

The Thoratec Pierce Donachy ventricular assist device is a paracorporeal pulsatile sac-type pump. The pumps lie on the abdominal wall. The Novacor device is an intracorporeal left ventricular assist device consisting of a one piece polyurethane sac and a pair of pusher plates. The pump is placed in front of the posterior rectus sheath. The Thermocardiosystems ventricular assist device is a pneumatically activated pusher plate intracorporeal pump. The device is placed between the left ventricular apex and ascending aorta.

ASSIST.DEVICES AND ARTIFICIAL HEARTS REGISTRY

A combined registry for the clinical use of ventricular assist devices and total artificial hearts was established in 1985. A recent report contained data on over 1500 patients. ${ }^{64}$ Support was instituted for postcardiotomy cardiogenic shock in 965 patients, 433 $(45 \%)$ of whom were weaned from support, but only $237(25 \%)$ survived to hospital discharge. A total of 544 patients received circulatory support in conjunction with heart transplantation, of whom 189 received a total artificial heart. Of the patients allocated to receive transplants, 436 required support for haemodynamic deterioration before orthotopic transplantation and 108 were supported after transplantation. Only 328 $(69 \%)$ patients supported before operation were actually given a transplant, of whom $217(66 \%)$ survived to discharge. The Kaplan-Meier survival rate at two years in this group was $65 \%$, which compares with $80 \%$ in patients given transplants who were not receiving mechanical support. However, the two year survival for patients requiring only univentricular support was $83 \%$. The incidence of multiorgan failure was substantially higher in patients bridged with a total artificial heart.

Several reports have described small series of

\section{Box C}

Criteria for ventricular assist device insertion

Maximal pharmacological support

Volume replacement

Intra-aortic balloon pump

Cardiac index $<1.81 / \mathrm{m}^{2} / \mathrm{min}$

Left atrial pressure $>20 \mathrm{~mm} \mathrm{Hg}$

Central venous pressure $>20 \mathrm{~mm} \mathrm{Hg}$

Oliguria

Mixed venous saturation $<60 \%$

Worsening acidosis

Pulmonary insufficiency 
patients supported with ventricular assist devices for one to 150 days with varying success. ${ }^{55-67}$ Critics claim that mechanical support as a bridge to transplantation results in donor organs being offered to those most critically ill and thus with the worst chance of success. However, as experience with devices increases, survival rates continue to improve and are approaching those achieved after transplantation without mechanical support. ${ }^{68}$ There are enthusiastic calls for increased and earlier insertion of devices. ${ }^{6970}$

Ventricular assist devices are usually implanted while the patient is receiving cardiopulmonary bypass. Anticoagulation regimens vary widely. ${ }^{71}$ Most centres give heparin to achieve an activated clotting time of 150-200 seconds. However, numerous different regimens have been advocated, including aspirin, warfarin, dipyridamole, protease inhibitors, and prostacyclin analogues. ${ }^{72}$ Bleeding is a primary complication of the technique. Experience with heparin bonded tubing avoiding systemic anticoagulation has not been successful. ${ }^{73}$ The other main complications are thromboembolism, infections, mediastinitis, haemolysis, antibody development, and neurological deficits. $^{74}$

The incidence of infection is high and is the usual cause of death. This has focused attention on completely implantable devices, and probably advances in bioengineering and biocompatibility will lead to the introduction of such devices over the next decade. A fully implantable left sided assist device developed by Novacor has reached clinical trials in the United States. ${ }^{75}$

The use of total artificial hearts has declined since 1989 (not entirely for clinical reasons) and is reviewed elsewhere. ${ }^{76}$ Thus far it has proved impossible to overcome the overwhelming infection which develops when the total artificial heart is implanted with the intention of it being a permanent device. However, outcome in patients bridged to transplantation with a total artificial heart is acceptable and compares with that in patients supported by ventricular assist devices. ${ }^{77}$

An interesting philosophy is exhibited by the $\mathrm{St}$ Louis group, which does not believe that outcome is improved by early transplantation after device insertion. Rather the group advocates weaning the patient from all other forms of support and then instituting a period of mobilisation and nutritional reinstatement. This approach is possible with implantable devices, and in this way patients present for transplantation in optimal condition. Aggressive mobilisation resulted in 26 of 32 patients sitting in a chair, 23 becoming mobile, and 21 using an exercise bicycle. $^{78}$ Twenty one of the 23 patients were ultimately discharged. The same group reported maintenance of a patient with a Symbion total artificial heart for 440 days. There is now evidence that earlier insertion of a ventricular assist device may actually improve outcome, ${ }^{77} 79$ and a reappraisal and broadening of the criteria for mechanical support has been advocated. ${ }^{74}$

\section{Conclusions}

There are various pharmacological and mechanical strategies for restoring vital organ perfusion. The best results are achieved when interventions are directed towards the specific haemodynamic derangements of individual patients, as detected by invasive monitoring. Furthermore, repeated evaluation of the response to treatment is necessary for the appropriate commitment of intensive care resources. Acute circulatory support presupposes that a re-establishment of cardiac function is likely, either by recovery or by surgical repair or transplantation.
1 Vincent $\mathrm{JL}$. Advances in the concept of intensive care. Am Hear $f$ 1991;6:1859-65.

2 Shoemaker WC, Appel PL, Kram HB. Oxygen transport measurements to evaluate tissue perfusion and titrate therapy: dobutamine and dopamine effects. Crit Care Med 1991;19:672-88

3 Pinsky MR, Summer WR, Wise RA, Perrmutt S, Bromberger-Barnea B. Augmentation of cardiac function by elevation of intrathoracic pressure. f Appl Physiol 1983;54:950-5.

4 Francis GS. Vasodilators in the intensive care unit. Am Heart f 1991;6:1875-8. 5 Leier CV, Binkley PF. Acute positive inotropic intervention: the catecholamines. Am Hear f 1 1991;6: 1866-70.

6 Royster RL. Intraoperative administration of inotropes in cardiac surgery patients. Fournal of Cardiothoracic Anesthesia 1990;4:17-28.

7 Bristow MR, Ginsburg R, Minobe W, Cubicciotti RS, Sugeman WS, Lurie K, et al. Decreased catecholamine sensitivity and $\beta$-adrenergic receptor density et al. Decreased catecholamine sensitivity and $\beta$-adrene
in failing human hearts. $N$ Engl $\mathcal{Y}$ Med 1982;307:205-11.

8 Reithmann C, Gierschik P, Sidiropoulos D, Werdan K, Jakobs KH. Mechanism of noradrenaline induced heterologous desensitisation of adenylate cyclase stimulation of rat heart muscle cells: increase in the level of inhibitory G protein $\alpha$ subunits. Eur I Pharmacol 1989;172:211-21.

9 Murphy MB, Elliott WJ. Dopamine and dopamine receptor agonists in cardiovascular therapy. Crit Care Med 1990;18:S14-8.

10 Schaer GL, Fink MP, Parillo JE. Norepinephrine alone versus norepinephrine plus low dose dopamine: enhanced renal blood flow with combination pressor therapy. Crit Care Med 1985;13:492.

11 Ruffolo RR, Spradlin TA, Pollock GD, Waddell JE, Murphy RT. Alpha and beta adrenergic effects of the stereoisomers of dobutamine. $f$ Pharmacol Exp Ther 1981;219:447-52.

12 Binkley PF, Murray KD, Watson KM, Myerowitz PD, Leier CV. Dobutamine increases cardiac output of the total artificial heart. Implica-

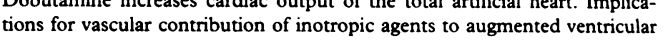
tunstion. Circulation 1991;84:1210-5.

13 Gillespie TA, Ambros HD, Sobel BE, Roberts R. Effects of dobutamine in patients with acute myocardial infarction. Am f Cardiol 1977;39:588-94

14 Tuttle RR, Pollock GD, Todd G. The effect of dobutamine on cardiac oxygen balance, regional blood flow and infarction severity after coronary artery narrowing in dogs. Circ Res 1977;41:357-64

15 Uretsky BF, Hua J. Combined intravenous pharmacotherapy in the treatment of patients with decompensated congestive heart failure. Am Hear $f$ 1991;6:1879-86.

16 Lollgen H, Drexler H. Use of inotropes in the critical care setting. Crit Care Med 1990;18:S56-60.

17 Puceat M, Terzic A, Clement O, Scamps F, Vogel SM, Vassort G. Cardiac alpha-1 adrenoceptors mediate positive inotropy via myofibrillar sensitization. Trends Pharmacol Sci 1992;13:263-5.

18 Lemmer JH, Bothma MJ, McKenney P, Gerren RA, Kirsh MM, Gallagher KP. Norepinephrine plus phentolamine improves regional blood flow during experimental low cardiac output syndrome. Ann Thorac Surg during experimen

19 Foex P. Evaluating the right ventricle. In: Stanley TH, Sperry RJ, eds. Anesthesiology and the hear. Dordrecht: Kluwer, 1990

20 D'Ambra MN, La Raia PJ, Philbin DM, Watkins WD, Hilgenburg AD, Buckley MJ. Prostaglandin E1. A new therapy for refractory right heart failure and pulmonary hypertension after mitral valve replacement. $\mathcal{f}$ Thorac Cardiovasc Surg 1985;89:567-72.

21 Fry ETA. Hemodynamic management of patients awaiting cardiac transplantation: stabilization, optimization, and prevention of complications. Coronary Antery Disease 1992;3:774-82.

22 Larach DR. Cardiovascular drugs. In: Hensley FA, Martin DE, eds. The practice of cardiac anesthesia. Boston: Little Brown and Co, 1990.

23 Murali S, Uretsky BF, Reddy S, Tokarcyzk TR, Betschart AR. Reversibility of pulmonary hypertension in congestive heart failure patients evaluated for cardiac transplantation: comparative effects of various pharmacologic agents. Am Heart f 1991;122:1375-81.

24 Ghosh S, Gray B, Oduro A, Latimer R. Dopexamine hydrochloride: pharmacology and use in low cardiac output states. Jourmal of Cardiothoracic pharmacology and use in

25 Jaski BE, Peters C. Inotropic, vascular and neuroendocrine effects of dopexamine hydrochloride and comparison with dobutamine. Am $\mathcal{f}$ Cardiol 1988;62:63-7C

26 Leier CV, Binkley PF, Carpenter J, Randolph PH, Unverferth DV. Cardiovascular pharmacology of dopexamine in low output congestive heart failure. Am $\mathcal{C}$ Cardiol 1988;62:94-9.

27 Bass AS. Contrasting effects of dopexamine hydrochloride on electrolyte excretion in canine kidney. I Pharmacol Exp Ther 1990;253:798-802.

28 Gray PA, Bodenham AR, Park GR. A comparison of low dose dopexamine and dopamine infusions in prevention of renal impairment in patients undergoing orthotopic liver transplantation. Intensive Care Med 1990;16:A149.

29 Leier CV. Regional blood flow responses to vasodilators and inotropes in congestive heart failure. Am $\mathcal{J}$ Cardiol 1988;62:86-93E

30 Gutierrez G, Palizas F, Doglio G, Wainsztein N, Gallesio A, Pacin J, et al. Gastric intramucosal pH as a therapeutic index of tissue oxygenation in
a critically ill patients. Lancet 1992;339:195-9.

31 Nouira S, Dhainaut JF, Garrauste MT, Brunet F, Armaganidis A, Schlemmer B. Hemodynamic effects of dopexamine in septic shock. Am Rev Respir Dis 1990;141(suppl):A139.

32 Leier CV. Current status of non-digitalis positive inotropic drugs. Am $\mathcal{f}$ Cariol 1992;69:120-9G.

33 Hajjar RJ, Gwathmey JK. Calcium sensitizing inotropic agents in the treatment of heart failure: a critical view. Cardiovascular Drugs and Therapeutics 1991;5:961-5.

34 Dage RC, Okerholm RA. Pharmacology and pharmacokinetics of enoximone. Cardiology 1990;77(suppl 3):2-13.

35 Harrison SA, Reifsnyder DH, Gallis B, Cadd GG, Beavo JA. Isolation and characterizations of bovine cardiac muscle cGMP inhibited phosphodiesterase: a receptor for new cardiotonic drugs. Mol Pharmacol 1986;29: diesterase:

36 Dibianco $R$. Acute positive inotropic intervention: the phosphodiesterase inhibitors. Am Hear f 1991;6:1871-5.

37 Boldt J, Knothe C, Zickmann B, Ballesteros M, Russ W, Dapper F, et al. The role of enoximone in cardiac surgery. Br $\mathcal{A}$ Anaesth 1992;69:45-50.

38 Konstam MA, Cohen SR, Weiland DS, Maartin TT, Das D, Isner JM, et al. Relative contribution of inotropic and vasodilator effects of amrinone induced hemodynamic improvement in congestive heart failure. $\mathrm{Am} \mathcal{f}$ Cardiol 1986;57:242-8.

39 Colucci WS. Cardiovascular effects of milrinone. Am Heart $\mathcal{f}$ 1991;121: $1945-7$. 
40 Hausen B, Heublein B, Vogelphol J, Von der Leyen H, Haverich A. Comparison of enoximone and piroximone in patients after mitral valve operation: a prospective and controlled study. I Cardiovasc Pharmacol 1992;19:299-307.

41 Vincent JL, Leon $M$, Berre J. The role of enoximone in the treatment of cardiogenic shock. Cardiology 1990:77(suppl 3):21-6.

42 Packer M, Carver JR, Rodehoffer RJ, Ivanhoe RJ, Dibianco R, Zeldis SM, et al. Effect of oral milrinone on mortality in severe chronic heart failure. $N$ Engl f Med 1991;325:1468-75.

43 Dibianco R, Shabetai R, Kostuk W, Moran J, Schlant RC, Wright R. A comparison of oral milrinone, digoxin, and their combination in the treatment of patients with chronic heart failure. N Engl $\mathcal{F}$ Med 1989;320 $677-83$

44 Curfman GD. Inotropic therapy for heart failure-an unfulfilled promise N Engl f Med 1991;325:1509-10.

45 Packer $\mathrm{M}$. Long term strategies in the management of heart failure: looking beyond ventricular function and symptoms. Am f Cardiol 1992;69:150-4G.

46 Pitt B. New approaches to therapy of cardiac failure. Current Opinion Cardiology 1992;7:404-7.

47 Goldstein RA, Gray EL, Dougherty AH, Nacarelli GV. Electrophysiologic effects of amrinone. Am f Cardiol 1985;56:25-8B.

48 Honerjager P. Pharmacology of positive inotropic phosphodiesterase inhibitors. Eur Heart f 1989;56:39-40B.

49 Hines R. Preoperative and postoperative use of inotropes in cardiac surgery. fournal of Cardiothoracic Anesthesia 1990;4(suppl 5):29-33.

50 Vincent JL, Leon M, Berre J, Melot C, Kahn RJ. Addition of enoximone to adrenergic agents in the management of severe heart failure. Crit Care Med 1992;20:1102-6.

51 Robinson RJS, Tcheervenkov C. Treatment of low cardiac output after aortocoronary bypass surgery using a combination of noradrenaline and amrinone. Foumal of Cardiothoracic Anesthesia 1987;3:229-33.

52 Olsen K, Kloya J, Fieldman A. Combination high dose amrinone and dopamine in the management of moribund cardiogenic shock after open heart surgery. Chest 1988;94:503-7.

53 Uretsky BF, Lawless CE, Verbalis JG, Valdes AM, Kolesar JA, Reedy PS Combined therapy with dobutamine and amrinone in severe heart failure. Chest 1987;92:657-62.

54 Murphy MB. The therapeutic role of drugs acting on cardiovascular dopamine receptors. Journal of Cardiotheracic Anesthesia 1990;4(suppl 1):23-6.

55 Van Trigt P, Spray TL, Pasque MK, Peyton RB, Pellom GL, Weschler AS The comparative effects of dopamine and dobutamine on ventricula mechanics after coronary artery bypass grafting: a pressure-dimensio analysis. Circulation 1984;70(suppl I): 112-7.

56 Kaplan JA, Guffin AV. The inodilators: an expanding role in the perioperative period. Foumal of Cardiothoracic Anesthesia 1990;4(suppl 1):27-31.

57 Maccioli GA, Lucas WJ, Norfleet EA. The intra-aortic balloon pump: review. Fournal of Cardiothoracic Anesthesia 1988;2:365-73.

58 Kantrowitz A, Tjonneland S, Freed PS, Phillips SJ, Butner AN, Sherman JL $\mathrm{Jr}$. Initial clinical experience with intra-aortic balloon pumping in cardiogenic shock. IAMA 1968;203:135.

59 Kantrowitz A, Freed PS, Cardona RR, Gage K, Marinescu GN, Westveld AH, et al. Initial clinical trial of a closed loop, fully automatic intra-aortic balloon et al. Initial clinical trial of a closed loop,
60 Alderman JD, Gabliani GI, McCabe CH, Brewer CC, Lorell BH, Pasternak $\mathrm{RC}$, et al. Incidence and management of leg ischemia with percutaneous wire guided intraortic balloon catheters. 9 Am Coll Cardiol 1987;9:524.

61 Kapoor AS. Application of intra-aortic balloon pump for circulatory support. In: Kapoor AS, Laks H, Schroeder JS, Yacoub MH, eds. Cardiomyopathies and heart-lung transplantation. New York: McGraw Hill, 1991.

62 Abiomed Inc. The pulse. Danvers, Massachusetts: Abiomed, 1992.

63 Moore CH, Dailey JW, Canon DS, Rubin JMO. Non-pulsatile circulatory support in 90 cases. ASAIO Trans 1992;38:M627-30.

64 Pae WE. Ventricular assist devices and total artificial hearts: a combine registry experience. Ann Thorac Surg 1993;55:295-8.

65 Farrar DJ, Hill JD. Univentricular and biventricular Thoratec VAD suppon as a bridge to transplantation. Ann Thorac Surg 1993;55:276-82.

66 McCarthy PM, Portner PM, Tobler HG, Starnes VA, Ramasamy N, Oyer PE. Clinical experience with the Novacor ventricular assist system. I Thorac Cardiovasc Surg 1991;102:578-87.

67 Marks JD, Karwande SV, Richenbacher WE, Jones KW, Doty DB, Millar $\mathrm{RC}$, et al. Perioperative mechanical circulatory support for transplantation. fournal of Heart and Lung Transplantation 1992;11:117-28.

68 Mulcahy D, Fitzgerald M, Wright C, Sparrow J, Pepper J, Yacoub M, et al. Long term follow up of severely ill patients who underwent urgent cardiac Long term follow up of severely ill pat.
transplantation. BMF 1993;306:98-101.

69 Poirier V. The quest for the permanent LVAD: we must continue, we must push forward. ASAIO Trans 1990;36:787-8.

70 Pennington DG. Circulatory support at the turn of the decade: a clinician's view. ASAIO Trans 1990;36:M126-31.

71 Miller LW. Mechanical assist devices in intensive cardiac care. Am Heart 1991;121:1887-92.

72 Tanaka K, Sato T, Kondo C, Yada I, Yuasa H, Kusagawa M, et al. Hematological problems during the use of cardiac assist devices: clinical experiences in Japan. Artif Organs 1992;16:182-8.

73 Bianchi JJ, Swartz MT, Raithel SC, Braun PR, Illes MZ, Barnett MG, et al. Initial clinical experience with centrifugal pumps coated with the carmed process. ASAIO Trans 1992;38:M143-6.

74 Reedy JE, Pennington DG, Miller LW, McBride LR, Lohmann DP, Noede NR, et al. Status 1 heart transplant patients: conventional versus assis device support. foumal of Heart and Lung Transplantation 1992;11:246-52.

75 Daniel MA, Lee J, LaForge DH, Chen H, Billich J, Miller PJ, et al. Clinica evaluation of the Novacor totally implantable ventricular assist system current status. ASAIO Trans 1991;37:M423-5.

76 Johnson KE, Liska MB, Joyce LD, Emery RW. Registry report. Use of tota artificial hearts: summary of world experience, 1969-1991. ASAIO Tran 1992;38:M486-9

77 Liska MB, Johnson KE, Emery RW. Current functional status of Symbio total artificial heart recipients after transplantation. ASAIO Trans 1992;38: 804-7.

78 Reedy JE, Swartz MT, Lohmann DP, Moroney DA, Vaca KJ, McBride LR, et al. The importance of patient mobility with ventricular assist device support. ASAIO Trans 1992;38:M151-3.

79 Ott RA, Mills TC, Eugene J, Gazzaniga AB. Clinical choices for circulatory assist devices. ASAIO Trans 1990;36:792-8.

(Accepted 21 May 1993)

\title{
Structural adjustment: the wrong prescription for Africa?
}

\author{
Dorothy E Logie, Jessica Woodroffe
}

\section{Health Centre, Earlston, Berwickshire Dorothy E Logie, general practitioner}

\section{Christian Aid, PO Box 100, London SE1 7RT Jessica Woodroffe, policy officer}

Correspondence to: Dr Dorothy E Logie, Cheviot View, Bowden, Melrose TD6 0ST

BMF 1993;307:41-4
It is the privilege of the rich to watch catastrophes from a balcony. Giraudoux.

As Africa emerges from the "lost decade" of the 1980 s it seems to be plunging into an even deeper quagmire of debt, ecological devastation, drought, and disease. Meanwhile we in the North watch the catastrophe, safe on our balconies, apparently unaware that our actions, and those of the institutions who represent us, are a major contributing factor to the continent's downward spiral of economic and social decline.

For years we have failed the ordinary people of Africa. Cast in the popular imagination of a bottomless pit for Western charity, the reality is that Africa, despite its increasing poverty, now transfers to the rich North $\$ 10$ billion a year, ${ }^{1}$ half of the debt interest due. Africa is not a lost cause: the people of Africa have shown resilience with a number of vibrant and innovative projects, communal associations, and small enterprises; they have struggled tenaciously to maintain their standards of living in the face of disasters. Africa can recover. What is required is urgent debt relief, fairer terms of trade, more democratic and transparent government, and economic programmes which are designed by and for African people rather than the rich in the North.

Malnutrition claims the lives of 11000 children each day, and exposure to disease is heightened by the fact that two thirds of all Africans do not have access to clean water for cooking and drinking. Sub-Saharan African countries are currently spending $50 \%$ more on servicing their debt than on the health and education of their children ${ }^{2}$ and less now on health per capita than they did in $1980 .^{3}$ As Africa's creditors, we should find this weighing heavily on our consciences. Despite paying out more than $\$ 1300$ billion between 1982 and 1990 , debtor countries are now $61 \%$ more indebted than they were in $1982 .{ }^{4}$

\section{How structural adjustment policies came about}

The story of Africa has not always been one of doom and gloom. During the 1960s and 1970s progress in education and health care was impressive. African governments consistently allocated a higher share of their gross national product to education and health than any other developing region except the Arab. states. ${ }^{3}$ The population with primary education doubled from $36 \%$ in 1960 to $79 \%$ in 1980 . From a meagre total of 1000 university graduates in 1960 , Africa was producing 7.0600 graduates 29 years later. ${ }^{3}$ Similar progress was made in health care, control of infectious diseases, hospitals, rural clinics, and community trained health workers. Child mortality more than halved between 1960 and 1990 (an achievement which took more than a century in the industrial world)..$^{5}$ The continent rode on a wave of hope. 